\title{
Action Research In A Business Classroom - Another Lens To Examine Learning
}

Janice Witt Smith, Winston-Salem State University, USA Gloria Clark, Winston-Salem State University, USA

\begin{abstract}
This research study looks at the implementation of an action research project within a blended learning human resource management class in employee and labor relations. The internal and external environment created conditions that converged in the Perfect Storm and resulted in an almost disastrous learning experience for faculty and students. What is critical about this project is that it could happen in even the most benign and calmest of waters. In an integrated system, the manipulation of one variable creates an impact on the other variables/systems within that environment. The failure to predict the impact and mitigate the damages can lead to disastrous results. The institution must be ready, at all levels, to implement and leverage technology to create distance-learning only environments for traditional students (and faculty) with a bias toward face-to-face educational experience.
\end{abstract}

Keywords: Action learning, pedagogy, on-line learning, Blackboard, learning theory

\section{INTRODUCTION}

$\mathbb{Q}$ mong the lofty goals of academe are the broadening of the students' intellectual and practice experience, increasing their content and business knowledge, sharpening their insight, honing skills, and preparing them to become contributing members of society. Some of the students were stellar performers who have successfully matriculated through K-12. Others were late bloomers or poor performers in high school who did not develop the study skills necessary to perform well at the collegiate level.

Consistent with the ever-changing economic landscape, the profession of education has navigated a series of tumultuous twists and turns as employers are expecting the end product (school of business graduates) to be able to contribute to the organization in meaningful ways and to bring fresh ideas and skills into the workplace. The 2007 SHRM Workforce Readiness study shows that both high school and college graduates have deficiencies when they enter the workplace (SHRM, 2007). For college graduates, the reported deficiencies are around critical and analytical thinking and communication skills (particularly oral skills). There is also a push among accrediting agencies to be able to assess the efficacy of one's treatment of "education" and to demonstrate that the school's mission and practices are consistent.

A number of university systems are experiencing huge budget shortfalls, due in part to being state-assisted rather than state-supported through public funds. As the economy worsens, the money available for funding colleges and universities may continue to decrease, by percentage of the universities' budgets. As a result of budget constraints and the desire of a number of students to engage in remote (or distance learning), some universities, and the University of North Carolina System in particular, are putting more emphasis on distance education. The use of distance education can increase class sizes and reduce number of faculty positions required, does not require brickand-mortar buildings, and increases the opportunity for technology utilization.

Among the ways posited to provide the best opportunity to accomplish the goals of academe is to provide cutting-edge technological training in conjunction with expert content instructional delivery, supported by appropriate assessment activities. The reported research study discusses an attempt to incorporate these factors into the learning experience of students in a single undergraduate course in employee and labor relations, a required course for students in the HR concentration and an elective course for students in the Certificate in HR Program. 
Immediately prior to this action research project, there was a restructuring of distance learning, particularly with respect to who had ownership of the various pieces that directly affected faculty - that is, requirements for distance learning courses, support for faculty in terms of training of web-based tools, approval of distance learning courses, and feedback to faculty concerning improvements to the courses. Before this restructuring, several different institutional entities were responsible for portions of these items, and faculty could receive approval in one area but have to deal with overlapping responsibilities/requirements from another area. Some faculty were able to create distance learning courses without adhering to any stated criteria, because department chairs controlled whether or not a course would be offered as a DL course.

This reported study looks at the implementation of an action research project within what was marketed as a blended learning human resource management class in employee and labor relations. The internal and external environment created conditions that converged in an educational Tsunami and resulted in an almost disastrous learning experience for faculty and students, where there was a huge onslaught of "practicality" against sound educational practice. What is critical about this project is that it could happen in even the most benign and calmest of waters. In an integrated system, the manipulation of one variable creates an impact on the other variables/systems within that environment. We provide a quick summary of what action learning/research is and potential benefits:

\section{ACTION LEARNING/RESEARCH}

- $\quad$ Sharing learning throughout multiple organizational levels

- Greater self-confidence and self-awareness because of the feedback and development of new insight

- $\quad$ Ability to ask better questions and to be more reflective

- Improved communications and teamwork

\section{RESEARCH QUESTION AND RATIONALE}

What is the appropriate mix/intervention of experiential learning, technology, and instructor-led teaching to provide a learning environment conducive to student success - to transition the faculty member from "Sage on the stage" to "Guide on the Side" when dealing with heterogeneous student population?

\section{LITERATURE REVIEW}

\section{Argument for use of technology in the classroom}

One of the purposes of web-based and technology-assisted courses is to provide an opportunity for students to engage with state-of-the-art technology, while concomitantly being able to schedule their learning experience(s) around their busy life schedule. This becomes increasingly important as both traditional and nontraditional students juggle work, family, community, and academic responsibilities. The literature on experiential learning has settled the case that there needs to be a good correspondence between the experiential activity (whether with technology or without it) that they are practicing and what is applicable in their world of work (Smith, 2003; Bassi, Benson \& Cheney, 1997; Duley \& Permaul, 1984; Knapper \& Cropley, 1985; Lenz, 1985; Knowles, 1978; Kolb \& Lewis, 1986; Burkhotter \& Schaer, 1984-5).

In addition, in order for their classroom experience to be meaningful, students must perceive a connection between what they do in the classroom and what is required of them in the other important realms of their lives. The implementation of technology facilitates the students' move from instructor-guided classroom learning to selfdirected and self-motivated experience-based and life-long learning (Knapper \& Cropley, 1985; Lenz, 1985; Knowles, 1978). Furthermore, Duley and Permaul (1984:20) found that "Students involved in experience-based learning also have improved attitudes toward learning in general. Students become more inquisitive, asking more substantive questions in class."

The acquisition and honing of technological skills is important for at least three reasons: (1) Technology provides access to a wealth of information; (2) Real-world application is essential to develop critical thinkers and 21 st century employees and entrepreneurs; (3) Students benefit from their ability to apply technology in real-world 
settings, to demonstrate competence (and even mastery) over technology, which makes them more competitive and valuable to the employer; and (4) Greater choice is afforded the individual who has both practical hands-on experience and the ability to marshal the experience and knowledge of others through technology.

Gagnon and Smith (2001:38-39) argue that experiential educational techniques, which may include computer-based or technologically oriented techniques could "enhance student learning attitudes, initiative, comprehension and retention; achieve higher levels of learning; offer business and other students the concrete learning experiences they prefer and which reinforce classroom principles; expose students to adult professionals and their problem-oriented focus; and challenge the students' social and communicative skills and ability for independent thinking and direction. From these encounters, the students' choice of careers, job prospects, and career advancements are also improved."

\section{BLENDED LEARNING}

In addition to technology-based training, students may also benefit from in-class interaction with a faculty member. According to Garrison and Vaughn (2008), "Blended learning is the thoughtful fusion of face-to-face and on-line learning experience." Chickering and Garrison (1987) also suggest that there are seven principles of good practice in undergraduate education. They are: (1) To encourage contacts between students and faculty; (2) Develop reciprocity and cooperation among students in the course; (3) Use active learning techniques such as case studies, discussion board, on-line assessments, project/workshop, and on-line blogging; (4) Give prompt feedback to the students (and this is increasingly important to millennial students; (5) Emphasize time on task - students want to know how long an assignment should take; (6) Communicate high expectations; and (7) Respect diverse talents and ways of learning.

Shibley (2009) identified a number of ways in which a blended course design could be improved: Using learning goals and creating opportunities for pre-class and post-class learning and rehearsal; use of both on-line and face-to-face interactions along with multiple communication channels; employing grading strategies with low-value and high-value assignments; and both seeking assistance and staying organized.

\section{RESEARCH MODEL}

The researchers' interest in incorporating technology was based on testing the following theoretical model, where the variables of interest are: (a) organizational readiness for technology; (b) external pressures; (c) technology-based education; (d) internal pressures; and (e) student outcomes. In this model, organizational readiness for technology impacts to what extent and in what ways technology-based education is incorporated, moderated by the level and types of external pressures on the institution to launch distance education. The type and extent to which technology is incorporated impacts student outcomes. This relationship is moderated by internal pressures (within university pressures) - the level and types of faculty support provided for technology inclusion, how ready the students are to embrace and successfully utilize technology, their individual and collective selfefficacy, and individual learning styles.

The External Pressures the institution may face include, but are not limited to: Accreditation requirements (AACSB-IME, SACS); University's Focus on research because of accreditation requirements, organizational culture, and funding; and Level of Budget and kinds and sources of funding available to ensure that cutting edge technology is employed.

Internal Pressures may serve as moderators between technology-based education and student outcomes and include: Faculty support; student readiness for distance education and technology implementation; individual and collective self efficacy; faculty teaching and communication styles; and students' learning styles. Organizational Readiness for Technology includes faculty expertise, type and complexity of technology, ease of use, infrastructure, organizational culture, underlying educational theory for inclusion.

Technology-based education includes program support, integrity of course selection, course content, ease of use of technology and resource support, student accessibility to technology, and technology as complement to 
rather than reason for course. Student outcomes may include Bloom's taxonomy of learning, student and faculty satisfaction, student and faculty engagement, student persistence, assessment scores, and graduation rates. The Research Model for this study is shown in Figure 1.

Figure 1: Research Model

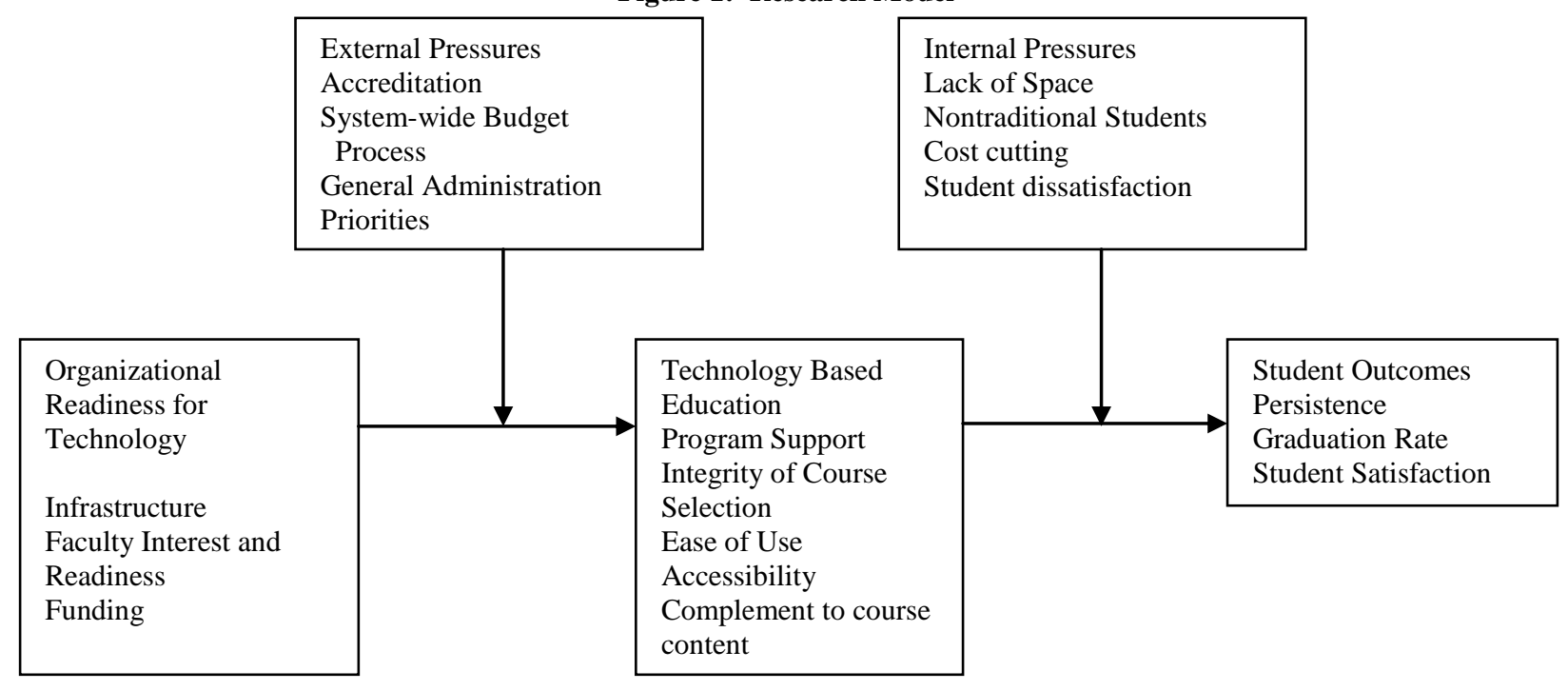

\section{RESEARCH STUDY}

Faculty member (hereafter referred to as "I") participated in an Action Research Institute funded by the oncampus teaching excellence center. This training provided the rationale for action research and provided examples of blended learning that enhanced the learning environment for students in several different classes on campus. It also provided faculty with an opportunity to interact with each other, the facilitators, and the educational technology experts on campus. Faculty were given the opportunity to submit an action learning research proposal for funding, which would be implemented in Fall 2009 semester. The action learning proposal had to be approved by the department chair and dean. The faculty members had to prove they had either successfully completed or refreshed human subjects training and this attestation was accompanied by an application for IRB approval, signed by faculty member, department chair and acting dean. A 3-4 member committee reviewed the proposals and selected several for funding. This reported study was approved, and I offered a plan for faculty interventions which required at some point that the two distance learning classes to have face-to-face interaction with me.

\section{RESEARCH DESIGN, METHODS, AND SAMPLE}

The institution of interest is a Master's I institution in the southeastern United States, which is part of a 17institution university system. The students are predominantly African-American, with a good mix between first and second generation college. There is a distance learning program; and within that program, there is an opportunity for distance learning courses created at this university to be part of the system-wide distance learning portal. The anticipated sample was of 30-35 non-traditional students and 15 traditional students enrolled in each of two distance learning classes. Actual sample was eight traditional students in a single DL class, since five of the six students in the second DL class were also in the first DL class. All students were between 20-24 years of age and had less than 3 months of career-level work experience (one student had had a three-month HR internship; the other students had part-time fast-food type counter type work). All eight students were African-American females who had only had one HR course prior to this course. Therefore, the integrated course interventions would be around individual student maturity and technology readiness levels versus cross-generation differences. In addition to the typical HR content, special attention would be paid to Sarbanes-Oxley and how organizations accounted for benefits, 
discrimination lawsuit settlements, and handled risk management issues. In addition, one of the teaching units was related to budgeting, financial analyses, and decision making utilizing accounting and financial data as well as benefits laws. Therefore, I sought and obtained the assistance of a senior member of the accounting faculty for assistance with development and instructional delivery of accounting content.

The focus on undergraduate learning included practices identified by Chickering and Gamson (2008). To incorporate these principles into the reported distance learning course, the following course components were included: (1) I contacted students prior to the course and communicated general information on own identity and interests and contact information, how the course fit into the overall HR program, the books that would be used, and the integration of technology with face-to-face interactions. (2) Students were told that we would use discussion board and that they would be assigned to small groups to facilitate deeper discussions of content. In addition, the students were asked to create a webpage and to engage in Water cooler discussions to enable them to build community. Questions in Water cooler related to self-disclosures and personal statements (their 30-second message to introduce themselves to others). (3) Active learning techniques such as case studies, discussion board, on-line assessments, project/workshop, and on-line blogging. (4) Feedback for the course was included through on-line quizzes created by the publisher which scored the quizzes immediately; verbal feedback in face-to-face class - "that was a great answer"; "I like where you're going, but you're a little off track"; and the use of follow-up questions. I also summarized discussions to ensure that students knew what the "correct" answer was, if there was only one correct answer. In addition, I responded in Discussion Board to ensure that the students remained on track through their on-line discussions. (5) Time on task was more difficult to incorporate. Their supplemental exercise workbook gave them a projected time that each activity should take. I required them to access Blackboard discussion board at least four times a week on three different days, responding to my question and the responses of their fellow students. I also included the number of hits that each Blackboard component had. (6) In my initial e-mail as well as in my orientation for the students, I emphasized my high expectations for them and their expectations for themselves. When providing them with feedback, I re-emphasized my belief that they were intelligent, articulate, and unique individuals whose answers needed some minor tweaking. (7) Finally, the purpose of this reported study is to discuss the ways in which diverse talents and ways of learning were respected and accommodated.

Shibley's (2009) suggestions for improving blended learning classes were incorporated when I ensured that detailed learning goals were provided to the students, both in the context of the course and in the context of the overall HR Program. Students were given exercises and activities in which to engage or about which to think before each scheduled class section. A discussion board was provided to get students to begin thinking about the material and a case study or exercise was also assigned to force them to read the text prior to the scheduled face-to-face meetings. The higher-level graded work was given to students to grapple with the content after they had had an instructor-led treatment of it to supplement what their thoughts were from the text, supplemental readings, introduction exercises and activities, and discussion boards. We scheduled face-to-face meetings as well as on-line activities to encourage student engagement and interaction. Multiple forms of communication included use of emails, announcements in Blackboard, handouts, face-to-face communication, and telephones. Students had assignments that they had to download from Blackboard or other links that I provided, videotapes through You-Tube and other media resources, as well as the national SHRM website and its links. A section on electronic links was provided in the resources section of their Blackboard course. Students rarely called to have their issues resolved in real time but relied on electronic communications or our face-to-face meetings. However, if students saw me on campus, they were likely to ask me questions related to the class. Because of the challenges we had throughout the semester and the use of multiple methods of communication, there were many opportunities for the proverbial ball to be dropped. Digital dropbox was not the preferred vehicle for turning in homework for the students, and they often duplicated their efforts by having back-up plans - they would "try" digital dropbox, then send the homework assignments to my home business and university e-mail accounts.

\section{ACTION LEARNING}

"Action learning is both a process and a powerful program that involves a small group of people solving real problems while at the same time focusing on what they are learning and how their learning can benefit each group member and the organization as a whole" (Marquardt 1999:4). In this case, action learning is taking what happens in the internal and external environment, through observation, experience and feedback and making 
adjustments in the course to facilitate a better learning experience for the students. Typically, the six steps in action learning are: Problem Identification, Planning, Action, Observation, Reflection, and Implications for Practice.

\section{PROBLEM IDENTIFICATION}

The purposes of this action learning project are fourfold: (1) To ascertain how and to what extent one would use technology to enhance learning and the viability of distance education for students at the institution of interest. (2) To utilize sound educational theory around pedagogy versus adult learning theory (andragogy) in practice. That is, how does one utilize the tenets of these theories in leveraging instruction for a heterogeneous class with traditional on-campus students with concentration in field, distance learning students who access course through UNC Distance Learning Portal, and distance learning working professionals enrolled in a certificate program? The traditional on-campus students are required to take this course as part of the HR Concentration. Currently, the Management major is not offered as a distance learning program; therefore, the HR concentration should not be offered as a distance learning program. The working professionals have this course as one of several selections among which they might choose four out of six courses for their Certificate Program. The course is also available to other business and non-business students as an elective if they have met three pre-requisites, whether seeking to earn a minor or taking for their own edification. (3) To determine if there is a need for differentiated instruction; and, if so, what are the most effective tools and practices, and what levels of support are available for the faculty meeting; and (4) To capture the experiential learning of the students and faculty members as adjustments are made to the class based on JIT instructional delivery, feedback, and assessments.

\section{PLANNING}

The Action Research Institute and Proposal Review were described earlier. Part of the planning process was the inclusion of faculty blogs which included observations and reactions to various events which enhanced or detracted from the students' overall learning environment.

\section{ACTION, OBSERVATION, REFLECTION, AND IMPLICATIONS FOR PRACTICE}

The action, observation, and reflection portions of this project were captured in a faculty blog. Below are summaries of the challenges that were experienced in this course, categorized by institution's miscues and student challenges. A sample blog entry is shown in Attachment 2.

\section{Institutional Miscues and Snafus - Storm Clouds are Gathering}

\section{Course scheduling}

The department chair offered one of the two agreed-up classes only as a distance learning class as part of the pre-registration process. This class, created for nontraditional, mature, and independent learners was the only section of the course offered to the traditional, on-campus students. The course is also offered only once per year. This means that a distance-learning course constructed for one age and experiential group was mandated for traditional students from another norm group, who were in other classes on campus together where they interacted face-to-face. The second course incorporated into the action research (and which was required for HR concentration students) and only offered once per year, was not offered to the students at all. This required course was only offered in the Fall of each semester, because of other course requirements that they needed to complete in Spring, one of which was their capstone course in Human Resource Management. I found out through the bookstore that the requested text for Compensation and Benefits could not be ordered because the course had not been included in Banner (the course registration, grade recording, and financial platform). The department chair was notified, and I contacted the students who had pre-registered for MGT 4337 - Employee and Labor Relations via e-mail and advised them that MGT 4335 - Compensation and Benefits would also be offered in the Fall 2009, and that both classes would be offered as blended learning courses. 


\section{On-Line Courses}

I had received a grant a year prior to create an on-line HR Certificate Program for working professionals. The courses were due by June 30, 2009. This grant allowed the six classes in the HR Concentration to be created as on-line courses, but the population of interest was working professionals with career-level experience in the field and the equivalent of an associate's degree (and the degree did not have to be in business or a business-related area). The department chair required that the traditional students take the same courses along with the working professionals, without any pilot testing to ensure that it was appropriate for that group. The texts that were embedded in the original DL classes were not appropriate for the traditional students. The primary text for compensation did not have the "bells and whistles", clipart, "sexy" pages to which undergraduate students tend to gravitate. It also did not provide the on-line support that traditional students need. We were under an institutional mandate to ensure that all texts were ordered by early April, so that discounted texts could be found. Because the texts could not be ordered before the classes were actually included in Banner, this created another complication. The compensation text was a "nuts and bolts, this is how we do compensation" type of text for someone who was actually working in an HR department. The Employee and Labor Relations texts were a new labor relations and collective bargaining text supplemented by the required text for their pre-requisite MGT 4348, Human Resource Management and Employment Law text, which provided legal background, employment relationship, discrimination, the legal practice part of Human Resource Management. Five of the six students in the compensation and benefits course were also in the employee and labor relations course. All of the students were African-American women except the one student only in the Compensation and Benefits course who is an Asian female with some difficulty speaking and understanding English. The undergraduate students in the traditional course were HR Concentration students who will be required to take the national certification exam in Human Resources to complete their program. The students in the Certificate Program did not have that as a requirement and would not be allowed to take the capstone class in HR.

Several requests were made to the department chair to allow a section of both classes for the traditional HR students, because the courses were not constructed with their level and needs considered. Department chair felt that a "good" faculty member would be able to simultaneously teach across levels, revamp the course for one group, learn and leverage new technology, account for contamination of students having face-to-face classes on campus together, and overcome the lack of soundness in having three on-line classes for students in a new six-course HR concentration. In addition, he had moved me to an off-campus so that the students were physically distant from me but could interact with their other faculty members.

\section{System Changes}

An administrative change occurred in which a decision was made to integrate Blackboard (course delivery system) with Banner (course registration and grading system). Administrators were added as "faculty" in all of the Blackboard classes, which gave them the same access to the course as the actual teaching faculty member. No trace of their entry into Blackboard would be provided to the actual instructional faculty. The department chair had access to grades, e-mails, homework, etc. The rationale for this change was supposedly to allow department chairs to know when mid-term grades were recorded. I requested that the Faculty Senate delve further into this, because that type of "Big Brother" scrutiny seems to violate faculty rights on so many levels.

On the other hand, only students registered in the course through Banner were allowed to access the course through Blackboard. A student dropping the course would have their data pulled out of Blackboard without any notification to the faculty member that the student had dropped. The faculty orientation to the changes also indicated that all data related to that student would also disappear - including discussion board entries, grades, etc. A new university policy was implemented that the students could be administratively dropped if they failed to attend the first two days of class, but they could appeal it. Once they were dropped and until their appeal was approved, there was no way for them to enter Blackboard to find out what work they had to do or provisions made for them to do make-up work. No policy was established as to whether or not their missed work was considered "zero" or if faculty had to provide opportunity for them to make up work. 


\section{Technology Changes}

A fourth challenge experienced was the technology challenges that occurred at the beginning of the semester. The file copy protocol in Blackboard malfunctioned, and duplicate copies of the DL Courses created and submitted June 30, 2009, were not made. The Blackboard shell that was automatically copied for each Banner course (official university course) did not include any of the course content that I had created over the course of the summer. That meant that until the glitch was fixed, I had to provide content and links via phone, e-mail or through face-to-face interactions with the students. Loading the material into the newly created shell did not provide students with access when the corrected shell was completed. The existing course shell would be made unavailable when the correct Blackboard shell was made available. The notice about the Blackboard file copy problem was sent to faculty during the summer, before our return to campus in mid-August. When faculty returned, many of their mailboxes, including mine, were full because of the number of e-mails sent over their non-contract period. Because memory space for e-mail is severely limited and only files deleted on campus are actually deleted, the full mailbox continued to be a problem for the first four weeks of class. University-wide e-mails and updates on Banner Production, on-campus activities, student gatherings, and the like were constantly refilling the faculty mailboxes. On the first day of class when I had scheduled a face-to-face meeting to orient the students to the course (only traditional students populated the course - no true distance learning students were registered for the course), I demonstrated Blackboard through the course I had developed during the summer to show them functionality, but the students could not access the course because they were not recognized as enrolled in a summer course.

\section{Meeting Rooms}

A fifth major challenge that occurred as it related to institutional policy or department chair action is around my inability to get a room in which to meet with the students when face-to-face interaction was needed. The department chair would not allow me to use classroom space on campus. Despite the Assistant Vice Chancellor for Distance Learning approving the use of face-to-face interactions as a supplement to on-line learning as long as grades were not awarded for the in-class portion and participation was strictly voluntary, the department chair refused to allow this to happen. The department chair had approved blended learning model but no longer agreed to it being done. As a result, neither the students nor I knew on a week-to-week basis whether or not an opportunity for face-to-face interaction would occur.

The on-line course in which only traditional students were enrolled had been developed as part of a grant for working professionals.

\section{STUDENT EXPERIENCES AND LEARNING}

During the first meeting with the students in MGT 4337 (Employee and Labor Relations), they shared their experience with distance learning and self-assessed their learning styles. Six of the eight students enrolled in the course attended the session, held in a workshop room in the on-campus library. All six students were traditional students. The two absent students were also traditional, on-campus students but they did not attend. Perhaps they had not read their e-mails. The students who were present indicated that their mailboxes were already full and they offered other e-mail addresses. Four of the six students were very familiar with Blackboard. Two of the students had only used Blackboard for looking at their grades. See notes in Faculty Member's Blog, Attachment 1, for additional information.

\section{Learning Styles}

Students in this course are primarily audiovisual learners, who need to see and hear the material being delivered, be able to ask questions, get feedback on relevant examples, and to learn more about the field. These students have high value for handouts and supplemental materials and prefer "executive summary"/overview approaches to introducing units. The students communicated that they were angry because they were forced into two distance learning classes in their primary content area, when they needed to have face-to-face interaction with the faculty member with content expertise and real-life experience in the field. 
Adjustment(s) Made

Students were given the option of meeting with faculty member face-to-face for half of the sessions, but only on a voluntary basis with no grades awarded for face-to-face attendance. We agreed that every other session would be face-to-face and that faculty member would continue to try to find space on campus in which to meet. Students did not have transportation to travel to faculty member's downtown office, and, in any case, the faculty member could not request conference room to meet with students at the location. This was an extremely humiliating experience for the faculty member because it demonstrated her lack of power and input into the teaching experience for the student; went against sound practice in terms of meeting student needs; violated the institution's espoused interest in increasing graduation rate; and de-motivated students (through anecdotal evidence) who were highly interested in the profession. NOTE TO BLOG: What a travesty - students WANT to meet with and interact with a faculty member and are DENIED that opportunity. How many faculty would love to have that problem!?! Challenge for the faculty member is to make the adjustments without showing frustration to the students regarding the need for the adjustment.

\section{Computer Access}

Only two of the eight students had their own computers. The other six had to use university and public labs. Sound is not available in the open labs without use of headphones. The students can use headphones in the media lab in the library. Videos are embedded in the DL courses, but the students had not accessed them as of 9-2509. Because of the increase in number of Blackboard courses and requirement that all courses have Blackboard, students had difficulty accessing Blackboard, and some were kicked out of Blackboard in the middle of an activity.

\section{Adjustments Made}

The video clips were made "interesting supplemental content" versus an integral part of the course. There are insufficient computer stations in the library and a limitation on the amount of time students can be at a station. Only two of the students live on campus, and the budget cuts have resulted in fewer hours for the libraries and labs and fewer "live bodies" to help if there is work to be done. The material covered in the video clips was moved to discussion board and faculty member provided a summary of the material but included a provocative question.

\section{Course Pre-requisite}

Students scored poorly on their pre-assessment, with one student demonstrating knowledge of $70 \%$ of prerequisite course material and the other seven with $50 \%$ or less of the foundational information. Some of this is related to students not seeing the relevance between pre-requisite courses and course requirements in other courses. This is a new program, and students have to become accustomed to the knowledge that what is covered in each course is foundational for the next course. The student who did well was one who had had an HR internship and learned through her employer. Students were provided a list of the content areas that should have been covered in their foundational HR course. The students claimed that, based on this list, over $40 \%$ of the material was not presented to them or included in the texts that were used. I conducted a further investigation to confirm what the students had said.

\section{Adjustments Made}

I reviewed the syllabi of the pre-requisite course and found that the faculty had used an old catalog description to teach content and had failed to teach the content required with the SHRM Educational Curriculum template upon which the entire HR program was built. In addition, the faculty in the pre-requisite course changed textbooks mid-year and the two sections taught by junior faculty did not have either the same text or content. Because the integrative text was not utilized, the students did not have access to the on-line quizzes that were integrated into this course. As a result, the students also would not receive immediate feedback on their mastery of the essential course elements. It is a violation of copyright for me to bring those quizzes outside of the on-line environment if the text is not being used in the course. The missed content had to be incorporated into the reported course, making the content extremely dense and increasing the need for student interaction with the faculty member 
to remediate the weaknesses. Material from the on-line PHR prep course I had created for another semester was incorporated into the course to provide some summary treatment of some of the missed material. I notified the management faculty and the department chair and provided the detailed course descriptions for dissemination to junior faculty (instructor and newly hired tenure-track faculty member).

I introduced the critical foundational elements, provided a detailed handout in class and a second on line on the material covered, created a study guide to narrow the content focus, held a 2-hour tutorial on the material on the day of the test, and conducted an assessment on it. The grades on the assessment ranged from $10 \%$ to $90 \%$, with modal score of 50\%. Students had not mastered the material. They had two weeks to cover what should have been covered in 6-7 weeks. Consistent with assessments utilized in previous classes, the content is introduced, quickly assessed through recitation, re-taught as needed, and assessed. Prior classes have shown that the students are literally shocked when they have to craft handwritten responses to short answer and discussion questions. This reaction was consistent in this class, even though students were forewarned that they would have this test format and were provided with sample questions. They shared that they have become so accustomed to objective tests with multiple-choice, true/false, and fill-in-the blank questions that they have difficulty expressing themselves in writing. One of our university-wide initiatives is "Writing across the Curriculum." Students are expected to have written assignments in each class. In addition, the students have to become accustomed to my style, whom only one of them has had before; deal with having a distance-learning course whose on-line format is not to their liking; overcome not having had the material covered in previous courses and inconsistency between what they were taught in the courses; and now they have a change in testing strategy. To reduce the panic that students sometimes experience when they see a test for the first time, I gave them blank sheets of paper at the beginning of the test and encouraged to "do a core dump" of what they knew so that that information would not leave their heads when they saw the actual questions. I had prepared them for this technique prior to this class.

During the test-taking period, students who "went blank" could come to me for a reminder and re-directed toward that answer. Finally, prior to handing in their test for grading, the students could have me review it and suggest that they enhance particular answers, move in a different direction, or refocus on a point. Several students were sent back two or more times. The student performing the best finished the test in less than 1-1/2 hours. The student who did the worst arrived for the test 45 minutes late, had forgotten that it was short answer and discussion, and had only memorized small blocks of information in anticipation of a multiple choice exam. She spent only 20 minutes on the test before handing it in and did not want me to review it prior to her leaving.

After the test had been graded, I submitted the grades to the students and asked them to review it against their notes. In the next face-to-face class session, I reviewed material, discussed and returned the graded test so that the students had the actual questions in hand, and provided supplemental materials to further explain and provide application for the theories, concepts, laws, and perspectives. They were offered the option of retaking the test and having the grades averaged. Seven of the eight students selected the retake. One student scored $90 \%$ on the first assessment and did not need the retake. The student who had scored $90 \%$ on the original test had an opportunity to earn additional points by correcting her test and returning it to me. In this way, all students had an opportunity to better their performance. Five of the seven students taking the retest significantly improved their grades. The lowest-scoring student had the least improvement. Her first grade was 10\%; her second grade was 50\%. This student has had significant problems understanding the use of Blackboard, has not been available for three of the seven face-to-face sessions, cannot use digital drop box, has not purchased the primary text, and has only turned in $30 \%$ of her homework. That student has received performance warnings, has not solicited assistance, and has as her familiar refrain, "I just don't understand anything." This student was not a good candidate for an on-line course.

The second test was offered as a take-home test with combination of objective and short-answer/discussion questions. This forces the students to read the text and supplemental materials, requires writing as well as critical thinking, and allows them to partially remain in their test-taking comfort zone. In addition, multiple choice tests constitute the majority of the PHR certification exam test. 


\section{Course Design}

Three of the eight students did not understand the course syllabus, which had been approved by instructional technologies, faculty reviewers, department chair and faculty member. They wanted to receive a weekly e-mail that told them what their homework was and when it was due. They did not like the use of the grading rubrics, they felt they were too detailed. Five of the students felt the syllabus was extremely detailed and very clear and did not understand why their classmates were having difficulty. Two students wanted longer period for completing work and reading material. Their lives were too busy and they had too many distractions to keep track of the work. They wanted a weekly e-mail to remind them of what graded homework was due and what they were to read for that week. I declined to make this adjustment.

When asked how much they understood about the syllabus so that their understanding could be calibrated, three of the students related they were not textual learners and had not gone through the material.

\section{Adjustment Made}

I reviewed the syllabus with them for the third time, walking through course requirements, due dates, expectations, rubrics, theory behind on-line learning, and the like. I re-emphasized the importance of reading, understanding, and utilizing the syllabus to stay on track and to perform well in the class. No change was made in due dates, but I agreed to provide detailed study guides for them prior to tests.

\section{Technology}

Technology included in Blackboard was digital drop box, discussion board, links to websites, PDFs for download, including power point presentations, and videos. In addition, the students were assigned the creation of an HR workshop on some aspect of employee and labor relations. They were asked to choose from a list of topics and were given detailed instructions on what the workshop should include. On September 1, 2009, they were given additional instructions and reminded to select their topic, since the workshop was due by 5 p.m. on September 21, 2009. Students were given another reminder about selecting their topic. On September 21, students did not have the workshops completed and were surprised that the on-line and hard-copy syllabus requirements were still in play. They were comfortable with Powerpoint, but they did not know how to use the other tools that were in the resources section of Blackboard - mind mapping, audio and video recording, clipart, embedding links, and the like. Two challenges remain here - students are not attending to the syllabus and the course requirements. Second challenge is around student comfort with technology. While Facebook and other social networks, twitter, texting and the like are within their realm of expertise, they have done poorly with digital dropbox, discussion board, and incorporating technology in their presentations.

\section{Adjustments Made}

Changed the format of the rest of the semester to get students more engaged in their own learning. Chapter content would be taught by the students to each other through their workshops. Criteria for workshops were again provided; they were allowed to choose their chapter, they were to focus on 5 key concepts, supplement with at least 5 other sources which would be provided to faculty member, and training requests would be sent through our university educational technology office. Blackboard discussion board interaction requirement was reduced students were meeting face-to-face with me and with each other and Discussion board was not their primary means of engagement. In order to measure their engagement, I retained the four entry per week requirement but reduced the number of days in which they made an entry from four to two. This would allow me to monitor the conversations and to provide them with feedback when they were on track. It allowed them to engage but removed the pressure of having to go on line more than four times, because they had to ensure that others had responded prior to them to enable them to have a conversation. We also discussed what the purpose of discussion board was (yet again) and I walked them through discussion versus making an entry by accessing the discussion board and showing them their pattern of responding. Because their entries in Blackboard are visible to each other, I did not deem it a violation of privacy by having this displayed on the screen. They are required to respond both to the overarching question and the input from each other. When we debriefed on this discussion of discussion board, it was clear that 
the light bulbs had "gone off" for them. In previous questions, Blackboard was used as an opportunity to answer a question from the faculty member and not to build a learning community among the group.

I did not make any modification to requirement for students to put graded assignments into digital dropbox. They need to be responsible for their own learning and track their process. I did not agree to e-mail them with assignments or provide an announcement related to assignments. I did agree to use announcements to provide additional instructions to students on assignments they had been given. I referred them back to the technology/questions section of Blackboard Discussion Board for questions that they have during the course. This would allow my response to be visible to the entire class instead of to one individual.

\section{Attempt at adjustment}

Made a request from educational technology center for assistance in training the students on the things that they did not know. Response from the instructional technologies was that they did not have time to respond to student questions and that they would only teach what I was already proficient in using. As a result of that meeting and interaction, further frustration built. NOTE TO BLOG: Am I teaching a technology course or am I utilizing technology to enhance an HR course. I provided feedback to the manager and his superior concerning this person's response, my displeasure, and my removing the technology portion from the Powerpoint - they can just do what they've always done. With having to remediate the knowledge deficits related to content, I cannot also teach the technology pieces that they are missing.

\section{KEY LEARNINGS FROM THIS EXPERIENCE}

A research forum presentation was made to the SBE faculty on this project. Several faculty expressed deep concern about the prohibition against the faculty member "I" meeting personally with the traditional students who had other on-campus courses. In addition, they were extremely disappointed that faculty input was not factored into the decision to offer the course as a distance learning course, nor did they support the use of a course designed for working professionals to be used with traditional undergraduate students. One such faculty member was extremely outspoken and voiced the sentiment, shared by others through their nodding and utterances of agreement, that this situation was fraught with inequitable treatment toward this faculty member and that accreditation could be jeopardized if this was a consistent pattern of behavior. Another asked the question what the Faculty Senate's role could be in resolving such situations.

With any organization change, a number of components must be in place before the change is instituted. In this case there was a lack of institutional readiness for technology. While parts of the infrastructure are in place, many pieces are needed. There are too many moving parts in the current environment, including the hiring of a new provost effective July 1, 2009, with her own ideas and perspectives; budget crisis which resulted in larger class sizes and fewer support staff. Both the school of business and the overall institution were undergoing preparation for Spring 2010 SACs and AACSB-IME re-accreditation visits.

Faculty are taught content relevant to their area during doctoral programs, but pedagogy and adult-centered learning are not part of what they learn. Faculty typically teach as they were taught. I had two courses that focused on adult learning theory and pedagogy. I have participated in a number of workshops and training opportunities at university and elsewhere and felt comfortable as an educator. When dealing with an administrator who did not understand pilot testing, norm groups, pedagogy or adult learning theory who made decisions which negatively impacted my courses (and ultimately my teaching evaluations), I found myself locked into a negative mode.

All content is not equally viable for distance learning treatment. The blended learning model was an ideal compromise between faculty-led and student-centered learning. When technology works well, it is a great complement. When it does not, as it did not in this case study, it is a huge disaster. With all of the institutional elements not in place, the unwillingness of administration to make adjustments to meet student needs, lack of leadership in ensuring that junior faculty taught the required content and were held accountable regarding textbook changes, etc., this initiative was doomed for failure. 


\section{AUTHOR INFORMATION}

Dr. Janice Witt Smith, SPHR, is founder and chief consultant with J.W. Smith and Associates, LLC, a human resource, leadership and organizational development and executive coaching company. She also is Professor of management at Winston-Salem State University in Winston-Salem, North Carolina. Dr. Smith consults in leadership development, team development, career development, change management, strategic planning, and human resource consulting, and issues related to workforce diversity. She is a published author whose work examines the experiences of racio-ethnic minorities and women in organizations.

Dr. Gloria Clark, CPA, is an associate professor of accounting in the Department of Accounting and MIS, at Winston-Salem State University in Winston-Salem, North Carolina. Dr. Clark consults in public and tax accounting and is a published author and motivational speaker. Dr. Clark has won numerous teaching and leadership awards and serves on the boards several prestigious organizations and honorary associations.

\section{REFERENCES}

1. Bloom, B.S. (1956, Ed.). Taxonomy of educational objectives: The classification of educational goals. Handbook I: Cognitive Domain, Dvid McKay Company, Inc., New York.

2. Brokaw, T. (1998). The Greatest Generation.

3. Burkhotter, B.B. and Schaer, B.B. (1984-85). The effect of cognitive style and cognitive learning in a nontraditional educational setting. Educational Research Quarterly, 9, 4.

4. $\quad$ Center for Creative Leadership (1988). Lessons of Experience. Jossey Bass: San Francisco, CA.

5. Chickering, A.W. and Gamson, Z.F. (1987). Seven principles for good practice in undergraduate education, AAHE Bulletin, p. 3-7.

6. Deal, J.J. (2007). Rethinking the Generation Gap: How Employees Young and Old Can Find Common Ground. Jossey Bass: San Francisco, CA.

7. Duley, J.S. and Permaul, J.S. (1984). Participation in and benefits from experiential education, Educational Review, 65, 3, 18-21.

8. Dustin, D.L. (1981). Classroom and experiential education. Improving College and University Teaching, 29 (No. 4), 166-168.

9. $\quad$ Enhance Learning with Technology (2009). Missouri Department of Education. http://members.shaw.ca/priscillatheoux/differentiating strategies.html/5/20/2009. Taken from (http://www.dese.state.mo.us/divinstr/gifted/pubref.htm\#INSTRUCTIONALS\%20STRATEGIES)

10. Fry, R., D.A. Kolb, and J.E. Althoff (Eds.). New Directions for Experiential Learning: Enriching the Liberal Arts through Experiential Learning, Jossey Bass: San Francisco, CA.

11. Gagnon, R. and Smith, J.W. (Spring/Summer 2001). Instructing the technical and behavioral aspects of total quality management: A cross-course experiential approach. The Journal of Business Education, 31-51.

12. Garrison, D. R. and Vaughan, N.D. (2008). Blended Learning in Higher Education: Framework, Principles, and Guidelines, Jossey-Bass.

13. Heathfield, S.M. (2008). Millennials. About.com. http://humanresources.about.com./od/glossarym/g/millenials.htm. 11/28/08

14. Knapper, C.K. and Cropley, A.J. (1985). Lifelong Learning and Higher Education, Croom Helm Ltd.: London.

15. Knowles, M.S. (1978). Contract learning. In Materials and Methods in Continuing Education, C. Klevins (Ed.), Klevins Publshing: Los Angeles, CA.

16. Kolb, D.A. and Lewis, L.H. (1986). Facilitating experiential learning: Observation and Reflections. In Experiential and Simulation Techniques for Teaching Adults, L.H. Lewis (Ed.). Jossey-Bass: San Francisco, California.

17. Lenz, E. (1985). The Art of Teaching Adults. Holt, Rinehart and Winston: Chicago, IL.

18. Raines, C. (2002). Connecting Generations; The Sourcebook.

19. Shibley, A.I. (2009). Putting the learning in blended learning. Online Cl@ssroom, A Magna Publication.

20. Smith, J.W. (2003). Technology infusion in to business curricula: A study of one human resource management class. Journal of the Academy of Business Education.

21. Wikipedia (2008: List of generations - Wikipedia, the free encyclopedia. http://en.wikipedia.org/wiki/List_of_generations. . .11/28/2008

22. Zappala, J.G. (2009). Promoting student participation and involvement in online instruction: suggestions from the front. 


\section{ATTACHMENT 1 - FACULTY BLOG}

The students are I are now out in the boat in the middle of the water, trying to do something innovating, exciting, cutting-edge, and instructionally sound. No shore is in sight; no rescue vehicles are around, and major storm clouds are gathering. Students and I are already frustrated about what we are experiencing, and this does not bode well for the semester. My focus is on how can I salvage the action learning project, adhere to the department chair's mandate, provide an instructionally sound course for the students, mentor and coach them, learning new technology, mitigate the damage to my teaching evaluations, and do the myriad of other things required of faculty. I am hopeful; I have help; someone on campus will listen to and support my efforts. Wrong! Below is my initial blog and in which I share my experience and thoughts about what is going on.

*******Faculty Member's Blog*******

\section{Faculty Member's Blog}

May 15, 2009 - Sent e-mail to students pre-registered in MGT 4337 class. Gave them information on textbooks, requirement that they join Ram SHRM and national SHRM and the 4-6 week lead time to have SHRM membership activated. Gave alternate source of textbooks, ISBNs and prices. Contacted Bookstore to ensure that books had been ordered. Was informed by bookstore manager, Bookstore manager stated that class was not on list and he couldn't order the book. It did show up in DL website but not on Banner. I sent e-mail to department chair that MGT 4335 class was not on line for pre-registration. Not aware of any notices sent out to encourage students to enroll in course for Fall2009. In MGT 4337 e-mail, I reminded students that other class would be offered and is offered only once per year.

Changes were made to the learning goals and objectives table for MGT 4348 during meetings of management faculty (I only attended one of three meetings).

July 20 - Requested status of Action Learning Research Proposal. Primary reviewer has not yet reviewed it - he's on vacation. Will have out by end of week.

August 17 - Requested status of Action Learning Research Proposal. Was told it was approved, but letter would come out in a couple of days.

August 17 - Sent e-mail to HR students asking that they pre-register for both classes. Only 2 students in Compensation class. Requested face-to-face first meeting with students.

August 18 - Advised departmental faculty that the learning goals and objectives for the HR course were woefully inadequate. Junior faculty felt that they should start slowly and only introduce one objective. I advised that I had taught the class five times and had no problem with measuring (with whatever level of precision is currently available) several objectives, and that the purpose of the objectives was not to serve the faculty members' convenience but to help direct the program and to assess in a meaningful way if we were achieving what we promised students when they entered the HR concentration. Also explained that there was a disconnect between what was needed in MGT 4348 as a required course for MGT majors and what was needed as the foundational course for HR Concentration students. Because of resource limitations, we need to make the course work for both. Tuesday, August 18 - No classroom was assigned for DL courses for even exam administration. Requested classroom through administrative support person (in person visit to her office).

August 20, 2009 - Action research project approved. Forms completed for IRB approval were not forwarded by CETL to IRB. I was told I am responsible for getting that approval and resubmitting those forms.

Sent Academic Standards forms to learning objectives chair, dept. chair, and secretary for distribution to other members of the management "curriculum" committee. This committee claimed no knowledge of the course descriptions (despite having been employed in SBE at the time these were approved). The on-line catalog has not been updated to reflect the new course descriptions which were approved by ASCC in May 2008 and in effect for Fall 2008. 
Thursday, August 20 - Requested meeting with associate director in CETL for Monday, August 24, 2009, to ensure on track with Action Research Grant. Received response on Monday, August 24, that she was not available and she suggested earlier time noon - received e-mail at 11:25 a.m. and two hours away from campus. She was not available later that day due to departmental meeting.

Sunday, August 23 - No classroom assigned. Requested classroom again. MGT 4335 was on line but only had maximum enrollment at 1 . Requested that this be updated unless it was an independent study class.

Monday, August 24 - No classroom assigned. Called and requested classroom. Promised return call within $1 / 2$ hour did not happen. Called around campus to locate room for face-to-face since had already scheduled with students. Was finally able to reserve library workshop room \#127 and notified students. 4:35 p.m. Went to copy center to pick up syllabus, power points and handouts for tonight's class. Copy center was closed because technician had gone out on service call. Located technician in Admissions (per Dr. Felder) and asked if he would be returning to Copy Center so that I could pick up the copies that were ready for me. Retrieved copies at 5:15 p.m. Went to library workshop room at 5:20 p.m. to ensure that equipment was working, room set-up was appropriate, materials were available, dry erase markers were available. Worked with library worker who was a 2007 graduate of MIS program in SBE.

5:30 p.m. - Received e-mail from department chair in which DL faculty were forbidden to have face-to-face contact with students in DL classes. Too late to get in contact with students to cancel 6:00 p.m. meeting. Met with them in library and explained new instructions. Reminded students of requirement for national and Ram SHRM Membership and need to access the SHRM website, importance to their career as HR professionals. Five out of 7 registered students attended this session, with one student who needed permission to register for the class:

- $\quad$ All students had had DL classes before - 1 student found this to be excellent method for her - she is shy and does not like interacting with people very much (she wants career in HR)

$\circ$ Two students hated the DL classes and disconnected early

- Two students liked DL okay but would go to faculty member for additional face-to-face assistance

- One student stayed in DL class but did not maximize her learning - she was frequently behind and lacked the discipline to maintain currency in the course. She doesn't remember what she learned.

- All six students requested face-to-face meetings on more detailed information that would be covered on their PHR exam - employment relationship, discrimination, introduction to labor relations. After discussing the syllabus, all six traditional students felt that this class was more than regurgitation of factual knowledge, required critical thinking, ability to communicate orally and to interact with real people - they requested that we have at least half of the sessions face-to-face.

- $\quad$ Two students needed exceptions to be in class - one had pre-registered and was dropped from the course. The other had been given permission, she said, from new HR Programs Coordinator and department chair to be in class as co-requisite with MGT 4348. I explained that this was against policy, and that I did not recommend that she do this. She does not have the foundational knowledge to successfully complete the course. Department Chair had denied permission previously when I had made a similar request. Advisor had signed off on this, she stated that Department Chair and HR Coordinator had approved it, and she needed class to graduate in May 2010. Classes would not be offered again until Fall 2010. Based on need to improve graduation rate, I signed with note that I did so only because these two individuals had already approved it. Second student was told she was not allowed to be in the course because administrative assistant told her that she couldn't be in class. She had taken the pre-requisite, MGT 4348, but had earned a D. I told student that she needed to retake MGT 4348 to graduate, but because she had passed the course, she could enroll in MGT 4337. Explained that it would be a challenge for her since she had not done well in MGT 4348. However, she is graduating in May 2010 and cannot delay it until class is offered again in Fall 2010. Sent e-mail to administrative assistant telling her that this student could be in the class.

- $\quad$ Students were not assigned Walsh textbook in foundational HR course, although it was the integrating textbook for the HR concentration. One student indicated that they used a general management textbook for the HR class and not an HR textbook at all. Based on student feedback and the different levels at which they are in terms of their exposure to and knowledge of HR, it is necessary to add units to provide them with background information to facilitate their success in the class. The students could not answer basic 
questions about HR. This course has already been revamped to include teaching them about the basics of the employment relationship, employment contract, duties owed employee/employer, legal environment in which employment relationship operates and employment discrimination - all of which should have been thoroughly covered in MGT 4348. Whether this was a coverage issue or a recall issue is a question. However, all of the students stated that these materials were not covered; therefore, this would have to be a coverage issue. Students cannot afford to purchase the integrating text, so two copies of the text and exercise manual have been made available to them.

- $\quad$ Typical way they were administered exams - they were given $90 \%$ multiple choice exams with one or two discussion questions - exams were on honor, in timed environment, and they could not go back to the exam when submitted it. Advised that multiple choice review tests were provided by book publishers, and this was a good way for them to do a quick check, however, my exams are short answer and discussion questions which require integration of material and interpretation and application of laws.

- $\quad$ August 24 - Received mandatory material for inclusion in syllabus from a faculty colleague ( $3 \mathrm{pm}$ on Monday) - Revised syllabus again and sent to students along with handouts since they cannot access website. Student complained that her e-mails to my on-campus e-mail account were kicked back to her. She felt that I would have answered them had I received them. Provided them with my consulting business e-mail address so that on-campus technology problems would not be a hindrance to them.

- $\quad$ Banner and Blackboard interface does not allow for faculty to enroll students. Department chair is listed as instructor and can enter Blackboard classes at will, sending e-mails to students, inputting grades, adding material, etc. No trail is left of his/her entry into platform. Request for explanation from Department chair for rationale was not answered (Sent August 20, 2009). As of August 25, 7:30 am, no response from department chair. Sent letter of concern to Faculty Senate Chair and Faculty Senator as well as DL Coordinator.

- $\quad$ Blackboard shell is empty. DL class created is in separate shell and students cannot enroll in it. Students can enroll in empty shell. Requested assistance from System Administrator and referred to on-campus coordinator for assistance.

- $\quad$ August 25 - Requested exception to be able to meet with students face-to-face on occasion and that a classroom be assigned. Sent to associate dean, CETL and DL Administrator.

- $\quad$ Revised syllabus again to remove in-class attendance requirement and to add verbiage related to catastrophe assignments and process.

- $\quad$ Frustration level of faculty member - very high - no support within department or SBE; many administrative snafus which create challenges in building a program; failure of department chair to respond to inquiries or to promote the program; location of faculty member at an off-site location, which makes it difficult for traditional students to have any interaction with her, despite research that shows that AfricanAmerican students tend to be more relational and are more successful if they feel that caring. All six students attending the face-to-face session were African-American students. The students tried to reserve the library workroom for additional classes but were not allowed to do so. Students were reminded that we are not allowed to have classes, but that I can have conversations with them about HR if they would like.

- $\quad$ Frustration with having been assigned to DL classes when my strength is face-to-face motivation and interaction with students, providing opportunity to provide real-time answers to their questions and to excite them about the HR profession. Classes were created for working professionals with background in business and not for traditional undergraduate students matriculating in first college degree program. Expressed concerns to department chair that it was inappropriate to use certificate program DL classes for traditional undergraduates. Concerns were not addressed and input was not considered or even responded to. Faculty member's feeling is this is an excellent example of how to destroy a new program - lack of support, poor deployment of talent, poor leadership, inability of leadership to capitalize on creative talent and abilities of others and impact of leaders' personality flaws that limit vision and destroy initiative. What a great article that would be!

$* * * * * * *$ End faculty blog******* 